\title{
Synchronous bilateral breast cancer in a male
}

\section{María Caridad Rubio Hernández¹, Yenia Ivet Díaz Prado', Suanly Rodríguez Pérez¹, Ronald Rodríguez Díaz and Zaili Gutiérrez Aleaga ${ }^{2}$}

\author{
${ }^{1}$ Mastology Department, Cuban National Institute of Oncology and Radiobiology, 29 y F Vedado, Plaza, La Habana 10400, Cuba \\ ${ }^{2}$ Anatomical Pathology Department, Cuban National Institute of Oncology and Radiobiology, 29 y F Vedado, Plaza, La Habana 10400, Cuba \\ Correspondence to: María Caridad Rubio Hernández. Email: maria.rubio@infomed.sld.cu
}

\begin{abstract}
Male breast cancer, which represents only $1 \%$ of all breast cancers, is occasionally associated with a family history of breast cancer. Sporadic male breast cancers presenting with another primary breast cancer are extremely rare. In this article, we report on a 70-year-old male patient with bilateral multifocal and synchronous breast cancer and without a family history of breast cancer.
\end{abstract}

Keywords: male breast cancer, synchronous, bilateral, multifocal

Published: 04/12/2013

Received: 10/07/2013

ecancer 2013, 7:377 DOI: 10.3332/ecancer.2013.377

Copyright: (c) the authors; licensee ecancermedicalscience. This is an Open Access article distributed under the terms of the Creative Commons Attribution License (http://creativecommons.org/licenses/by/3.0), which permits unrestricted use, distribution, and reproduction in any medium, provided the original work is properly cited. 


\section{Summary}

Male breast cancer represents $1 \%$ of all breast cancers. It occasionally occurs in patients with a family history of this disease. Synchronous bilateral breast cancer in men is extremely rare. In this report, a 70-year-old male with synchronous bilateral multifocal cancer of the left breast (LB) with no family history of breast cancer is presented.

\section{Introduction}

Breast cancer is a rare disease in men. According to international statistics, this pathology represents $1 \%$ of all breast neoplasia, whereas in Cuba, it represents $0.8 \%[1,2]$.

Among the factors that predispose its occurrence, we include exposure to ionising radiation, the administration of oestrogens, and diseases related to hyperestroginisation, such as cirrhosis of the liver and Klinefelter syndrome [3].

Genetic factors such as the mutation of the BRCA1-2 genes or kinship are related to the incidence of this disease, although the majority of those affected do not present risk factors [4, 5].

Unlike its incidence in women, who have a bimodal age-frequency distribution, its incidence in men is unimodal, with a peak incidence at 71 years. It has a central, sub-areolar location, and nearly $85 \%$ of cases show up in a physical exam. The most common histological type is invasive (infiltrating) ductal carcinoma with an incidence of $85-90 \%$ [6-8].

Although the disease presents similarities in both genders, its rarity and the small number of cases do not allow the carrying out of clinical research necessary to develop optimum treatment. This is why treatment is based on empirical advances made in breast cancer in women [9].

In this report, we present a 70-year-old man with bilateral breast cancer, apparently synchronous, multifocal, and with differing histologies in the LB, with no family history of breast cancer. In this case, the clinical criteria for hereditary familial cancer are evaluated [1].

High risk

- Cancer at less than or equal to 40 years.

- Diagnosis of breast and ovarian cancer in the same individual.

- Two or more cases, one of which is less than 50 years old or bilateral.

- A case of breast cancer, less than or equal to 50 years and a case of ovarian cancer in a first- or second-degree relative.

- Three cases of breast and ovarian cancer in first- and second-degree relatives.

- Male breast cancer and breast or ovarian cancer in first- or second-degree relatives.

Moderate risk

- Two first-degree relatives if both have been diagnosed between the ages of 51 and 60 .

- A first- and second-degree relative (mother or sister, and maternal aunt or grandmother), if the sum of their ages is less than or equal to 118 years.

\section{Clinical case}

This is a 70-year-old white male with a history of type II diabetes mellitus. The patient denied any family history of breast or any other type of cancer. This information comes from a genetic and breast cancer consultation, in which the family history, physical examination, and mammography were carried out on the first-degree relatives of the patient. The patient came to the Oncology Institute complaining of lumps in both breasts for the past two months.

Upon physical examination, a hard lump, measuring $30 \times 20 \mathrm{~mm}$, was felt in the right breast (RB) and armpit, with an irregular surface, poorly defined edges, mobile, with fixation and retraction of the nipple-areolar complex accompanied by hard, mobile, and ipsilateral 
adenopathy. The LB presented a hard, irregular lump, measuring $20 \times 25 \mathrm{~mm}$, with poorly defined edges in the retroareolar region with hard, mobile, and ipsilateral adenopathy (Figure 1).

On performing the breast ultrasound, a solid, irregular lump was observed in RB, measuring $30 \times 25 \mathrm{~mm}$, of heterogeneous texture, with microcalcifications in its interior and adenopathies with a pathological appearance, while in the LB, a solid lump was observed, with a heterogeneous texture, measuring $22 \times 20 \mathrm{~mm}$, with irregular contours, located in the retroareolar region with no evidence of pathological adenopathies. The bilateral mammogram revealed the presence of a lump in the RB, with diffuse edges, infiltrates, measuring $40 \times 35 \mathrm{~mm}$, producing retraction and flattening of the nipple, with pathological microcalcifications in its interior, the spikes of the lump were close to the pectoralis major muscle, while in the LB, a lump was observed measuring $25 \times 20 \mathrm{~mm}$ with diffuse spiked edges, with pathological microcalcifications both within and outside it (Figure 2). Both tests were classified, according to the Breast Imaging-Reporting and Data System (BI-RADS), as a category $\mathrm{V}$ lesion: highly suggestive for malignancy.

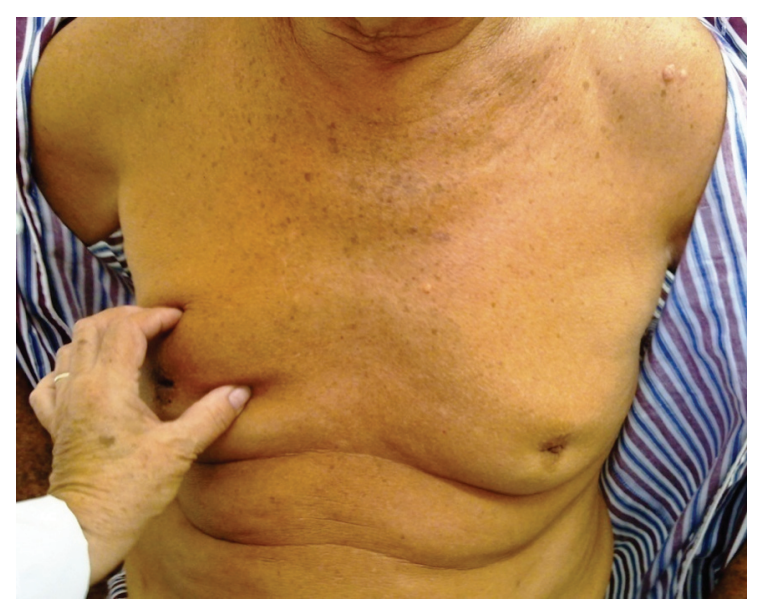

Figure 1. Patient aged 70 years with synchronous bilateral breast cancer.
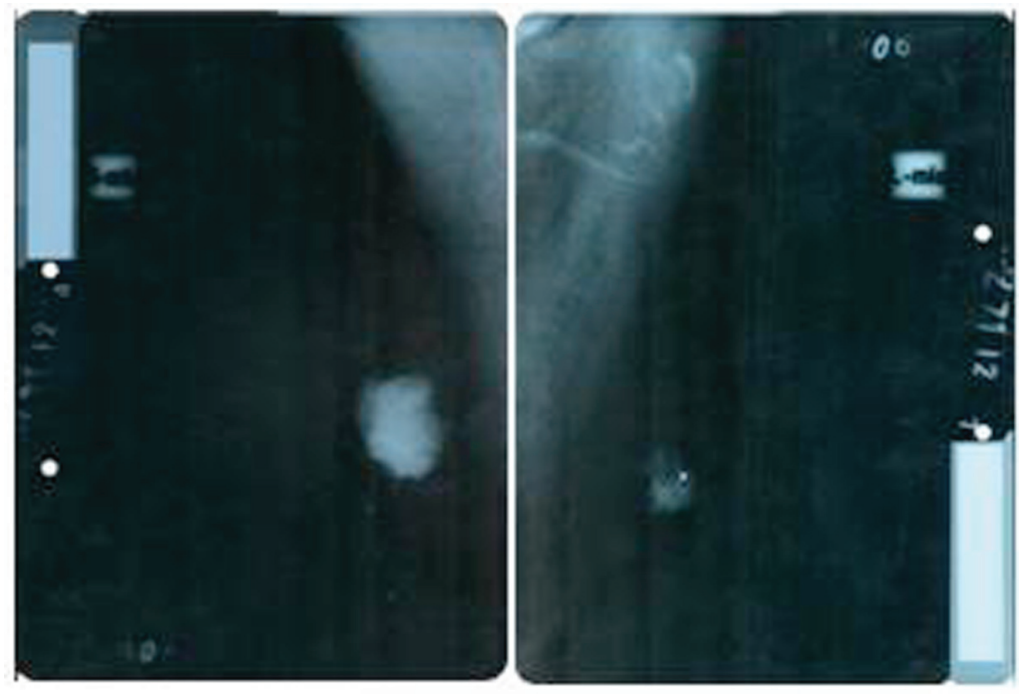

Figure 2. Bilateral mammogram: mediolateral oblique view showing the presence of lesions highly suspicious for malignancy, BI-RADS category V. 
A freeze biopsy was performed, and invasive papillary carcinoma was reported for both breasts. A bilateral modified radical mastectomy was carried out.

The histopathological examination revealed the presence of invasive ductal carcinoma in the RB, nuclear grade (NG) II, Bloms Richardson (BR) II, RE 45\%, RP 85\%, HER-2 +1, KI $6740 \%$ with vascular and lymphatic invasion, and a tumour size of $45 \times 40 \times 30 \mathrm{~mm}$. There were 11 positive nodes of a total of 20 analysed (11 of 20). In the LB, two (multifocal) lumps are reported, the larger measuring $23 \times 20 \times 15 \mathrm{~mm}$ corresponding to invasive ductal carcinoma, NG II, BR-II, RE 90\%, RP 90\%, HER-2 +1, KI 67 20\%, with papillary areas, infiltration of adipose tissue, neural invasion, and vascular and lymphatic permeation. The other lump corresponds to invasive papillary carcinoma, measuring $25 \times 15 \times 15 \mathrm{~mm}$ and presented multiple calcifications. The lymph nodes examined showed two positive lymph nodes (2 of 18) (Figures 3-5). The chest $\mathrm{x}$-ray, abdominal ultrasound, and bone scan carried out to assess the extent of the disease were within the norm.

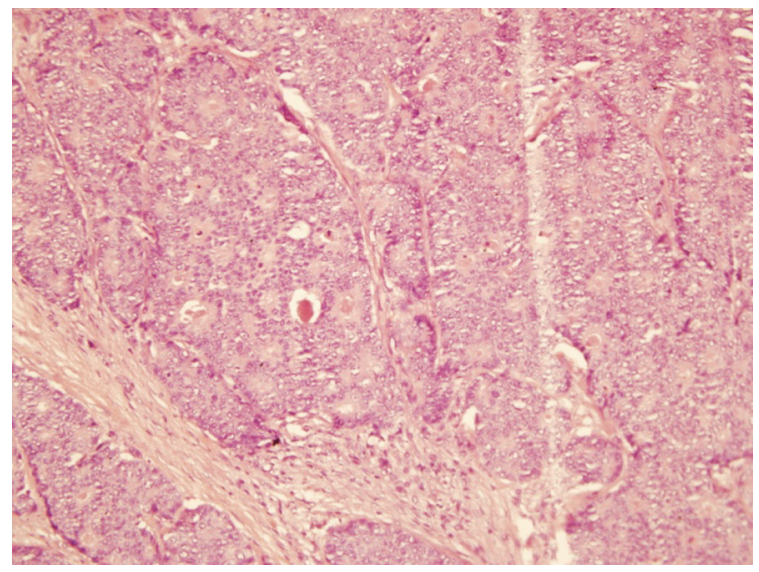

Figure 3. Haematoxylin-Eosin stain (20x). B12-2165: RB-invasive ductal carcinoma of intermediate-grade malignancy (NGII, BRII), measuring $4.5 \times 4 \times 3 \mathrm{~cm}$.
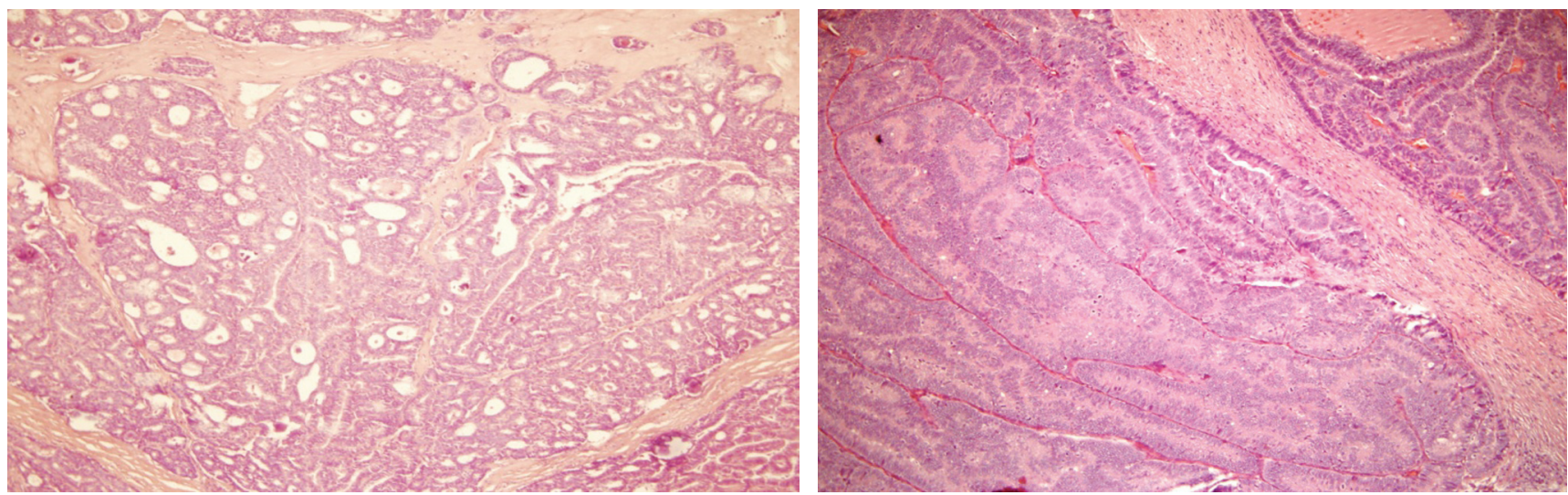

Figure 4. Haematoxylin-Eosin stain (20x). B12-2166: LB-invasive multifocal ductal carcinoma of intermediate-grade malignancy (NGII, BRII), with papillary and cribriform features, measuring $23 \times 20 \times 15 \mathrm{~cm}$. 


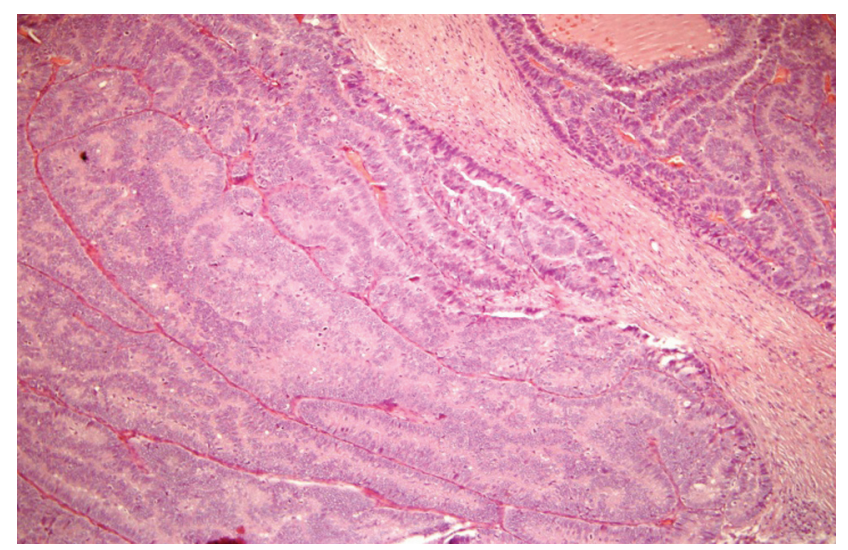

Figure 5. Haematoxylin-Eosin stain (20x). B12-2166: LB-invasive papillary carcinoma measuring $25 \times 15$ x 15 mm.

According to the pTNM classification, this corresponds to pT2N3M0, stage IIIC for RB and pT2N1M0, stage IIB for LB. The patient was assessed in a multidisciplinary consultation where chemotherapy treatment was decided upon: four cycles of Adriamycin/Cyclophosphamide and four cycles of Taxol, in addition to radiation therapy to both surgical beds and supraclavicular fossa, followed by hormone therapy (one tablet of Tamoxifen daily for five years). At the present time, the patient's condition is under control, and he is in follow-up with mastology.

\section{Discussion}

Breast cancer in men is a rare pathology. The median age at diagnosis is 60-70 years, although it can affect men of all ages. A bilateral, synchronous presentation is extremely rare, with an incidence of $1-2.5 \%$ of the total number of patients with breast cancer [5, 10-13].

Bilateral breast cancer is defined as the presence of an independent primary malignant tumour in each mammary gland; while the term 'synchronous' refers to the presence of primary tumours in both breasts, which are diagnosed simultaneously. According to McCredie, this term also includes the diagnosis of contralateral tumours that occur within the first six months following diagnosis of the primary tumour, and according to Heron, within the first year of the initial diagnosis $[10,15,16]$.

The most frequent histological type in men is the invasive ductal carcinoma (85-90\%). Other rarer invasive tumours are invasive (4.5\%) and mucinous (2.8\%) papillary carcinoma. Carcinoma in situ has a frequency of $10 \%$ and is mostly papillary (74\%) with a normally cystic presentation. Invasive papillary carcinoma is twice as frequent in men as it is in women (2-4\% versus 1\%) [17, 18].

With respect to the involvement of the lymph nodes in breast carcinoma in men, it has been observed that the more advanced the average age at diagnosis, the more likely that there will be lymph node involvement presenting at a more advanced stage [8].

In males, these tumours show a large oestrogen receptor (80-90\%) and progesterone receptor (73-81\%) expression, even higher than in women (75\% and 65\%, respectively). Some studies have shown a lower HER-2 expression in men (2-15\%) than in women (18-20\%), although the data are inconsistent $[19,20]$.

Due to the rarity of the disease, there are no controlled prospective studies that support a specific therapeutic management strategy. Therefore, almost all the management strategies in men are the result of retrospective studies of a series of cases and experience with women. The mainstay of treatment is based on the local and regional control of the disease with surgery and radiation therapy and in systemic control with hormone therapy and chemotherapy [21].

In the case of our patient, the histological types found correspond to those reported in the literature as the most frequent: papillary and invasive (infiltrating) ductal carcinoma, with multifocality with different histological types being truly rare [22]. The result of the studies of 
immunohistochemistry coincides with the reviewed literature, these highly endocrine tumours being responsive without overexpression of the HER-2 [23, 24]. Neither a family history of this pathology nor other risk factors associated with the disease were collected, so this is considered a sporadic and unusual case.

\section{Conclusion}

We are dealing with an uncommon presentation of breast cancer in men: synchronous, bilateral, and multifocal with different histological types in the LB, with no family history of the pathology, or related risk factors, which is why its publication is considered important.

\section{References}

1. Soriano JL, Rubio MC, López MV, Marinello JJ, Rodríguez M, et al (2013) Programa integral para el control del cáncer de mama en Cuba. Cáncer de mama. Guías de práctica clínica en diagnóstico y tratamiento. Reunión del consenso de 2013

2. (2012) Colectivo de Autores Anuario Estadístico (Cuba: MINSAP)

3. Hultborn R, Hanson C, Köpf I, et al (1997) Prevalence of Klinefelter's syndrome in male breast cancer patients Anticancer Res 17(6D) 4293-7

4. Wooster R, Bignell G, Lancaster J, et al (1995) Identification of the breast cancer susceptibility gene BRCA2 Nature 378(6559) 789-92. DOI: 10.1038/378789a0 PMID: $\underline{8524414}$

5. PDQ [website] USA (2012) National Cancer Institute [updated 13 Jan 2012; referenced 25 Jan 2013] Retrieved from http://www.cancer.gov/cancertopics/types/breast

6. Anderson WF, Althuis MD, Brinton LA and Devesa SS (2004) Is male breast cancer similar or different than female breast cancer? Breast Cancer Res Treat 83 77-86 DOI: 10.1023/B:BREA.0000010701.08825.2d PMID: 14997057

7. Gennari R, Curigliano G, Jereczek-Fossa BA, Zurrida S, Renne G, Intra M, Galimberti V, Luini A, Orecchia R, Viale G, Goldhrisch A and Veronesi U (2004) Male breast cancer: a special therapeutic problem. Anything new? (Review) Int J Oncol 24 663-70 PMID: 14767551

8. Giordano SH, Cohen DS, Buzdar AU, Perkins G and Hortobagyi GN (2004) Breast carcinoma in men: a population-based study Cancer 101 51-7 DOI: 10.1002/cncr.20312 PMID: 15221988

9. Burstein HJ, Harris JR and Morrow M (2011) Malignant tumors of the breast Cancer: Principles and Practice of Oncology 9th edn, eds VT DeVita Jr TS Lawrence, SA Rosenberg (Philadelphia: Lippincott Williams \& Wilkins) pp 14001-46

10. Ipiña JM, Gonzalez E, Noelia C, Armanasco E, Azar ME, Montoya D and Cristo Morgado C (2007) Cáncer de mama bilateral Rev argent mastología 26(93) 273-80

11. García-Mejido JA, Delgado-Jiménez C, Gutiérrez-Palomino L, Sánchez-Sevilla M, Iglesias-Bravo E and Caballero-Fernández V (2013) Synchronous bilateral breast cancer in a male Cir Cir 81(3) 225-7 PMID: 23769252

12. Sosnovskikh I, Naninato P, Gatti G, Caldarella P, Masullo M, De Brito LL and Luini A (2007) Synchronous bilateral breast cancer in men: a case report and review of the literature Tumori 93(2) 225-7 PMID: 17557578

13. Kahla PB, Cassaro S, Vlandimir FG, Wayne Mg and Cammrata A (2005) Bilateral synchronous breast cancer in a male Mt Sinai J Med 72(2) 120-3 PMID: 15770342

14. Al-Saleh N (2011) Bilateral ductal carcinoma in situ (DCIS) in a male breast: a case report Gulf J Oncol (9) 68-72 PMID: 21177213 
15. Sun WY, Lee KH, Lee HC, Ryu DH, Park JW, Yun HY and Song YJ (2012) Synchronous bilateral male breast cancer: a case report J Breast Cancer 15(2) 248-51 DOI: 10.4048/jbc.2012.15.2.248 PMID: $\underline{22807945}$ PMCID: $\underline{3395751}$

16. González Ortega JM, Gómez Hernández MM, López Cuevas ZC, Morales Wong MM and Fernández Martel MI (2005) Cáncer de mama bilateral. Estudio clínico-patológico de 30 años (España: Complejo Hospitalario de Ciudad Real) [referenced 4 Feb 2013] Retrieved from http://www.conganat.org/7congreso/trabajo.asp?id trabajo=128\&tipo=2\&tema $=42$

17. Orea Estudillo D, Hernández Rubio A, García Rodríguez FM, Gil García R, Varelas Riojano F and Jiménez Villanueva X (2007) Cáncer de mama bilateral. Experiencia de 10 años en la unidad de Oncología del hospital Juárez de México Cirujano General [Internet magazine]29(4) [approx. 15p] Retrieved from http://new.medigraphic.com/cgi-bin/contenido.cgi?IDREVISTA=8\&IDPUBLICA CION=1496

18. Burga A, Fadare O, Lininger RA and Tavassoli $F(2006)$ Invasive carcinoma of the male breast: a morphologic study of the distribution of histologic subtypes and metastatic patterns in 778 cases Virchows Arch 449 507-12 DOI: 10.1007/s00428-0060305-3 PMID: 17058095 PMCID: 1888721

19. Lemoine C, Mayer SK, Beaunoyer M, Mongeau C and Ouimet A (2011) Incidental finding of synchronous bilateral ductal carcinoma in situ associated with gynecomastia in a 15-year-old obese boy: case report and review of the literature $J$ Pediatr Surg 46(9) e17-20 DOI: 10.1016/j.jpedsurg.2011.06.010 PMID: 21929970

20. Mesa G, Matute G, Estrada M, Ocampo A, Restrepo C and Estrada J (2011) Cáncer mamario en hombres Revision del tema Rev Colomb Cir 26 293-307

21. Gómez RC, Zambrana F, Serreno M, López M and Casado E (2010) Male breast cancer Cancer Treat Rev 36 451-7 DOI: 10.1016/j. ctrv.2010.02.002

22. Ottini L, Palli D, Rizzo S, Federico M, Bazan V and Russo A (2010) Male breast cancer Crit Rev Oncol Hematol 73 141-55 DOI: 10.1016/j. critrevonc.2009.04.003

23. Ying MW, Agrawal A and Cheung KL (2005) The other half of breast cancer: a review of male breast cancer $J$ Mens Health Gend 2 406-13

24. McQueen A, Cox J, Desai S and Moore R (2007) Multifocal male breast cancer: a case report Clin Breast Cancer 7(7) 570-2 DOI: 10.3816/CBC.2007.n.014 PMID: 17509167 